\title{
To get more than enough
}

\section{Colin Norman reports on a massive research effort to combat hunger and malnutrition proposed in Washington last week}

\begin{abstract}
A RECORD harvest in the key grain producing countries last year and the prospect of another bumper wheat crop in the United States this year have temporarily removed famine and hunger from the daily headlines. But, with international grain reserves still at a dangerously low level, a catastrophic food shortage in many parts of the world is still only one poor harvest away. Moreover, even if luck continues to hold, there's little room for complacency: according to widely accepted estimates, between 500 and 1,000 million people are already chronically underfed, and rapidly increasing population in most developing countries is continuing to drive up food demand.
\end{abstract}

Against that grim background, it may seem like the height of folly to suggest that "it should be possible to overcome the worst aspects of widespread hunger and malnutrition within one generation". But that is the conclusion of a major study published last week by the National Academy of Sciences*. One of the most intensive investigations of world food prospects yet put together, the study took two years and involved some 1,500 people; the effort was coordinated by a committee headed by Harrison Brown, professor of geochemistry at Caltech.

The committee's optimism is founded on the expectation that a massive research effort on a broad spectrum of agricultural, social and population problems could lead to a doubling of agricultural production in the developing countries and more equitable distribution of food during the next quarter century. Such an expansion would, in theory, be sufficient to cope with increased food demand from rising population and affluence, and it would also provide an increase in food consumption per capita worldwide.

But the committee is also quick to acknowledge that science and technology will not alleviate widespread hunger by themselves. Basic social changes will be needed to ensure more effective distribution of available food and to reduce poverty, though the committee's report does not advocate any specific social remedies. More attention to nutrition policies will also be required in both the poor and affluent countries, and there must also be renewed efforts to hold down the explosive rate of population

*World Food and Nutrition Study, Printing and Publishing Office, National Academy of Sciences, 2101 Constitution Ave NW, Washington DC $20418, \$ 6.95$. growth, the committee states.

Given the complexity of the world food problem, the committee's optimism is surprising. During the past few years there has been a fundamental shift in the food picture as grain reserves have dwindled to less than a third of their 1970 level and more countries have become dependent on the North American breadbasket to meet their food demands. After a decade of stability, crop prices have fluctuated wildly, aggravating problems of hunger and malnutrition in the poorer countries. And the increasing reliance on North American agriculture to meet world demands raises the grim possibility that a failure of the United States and Canadian harvest would have dire consequences.

\section{Numerous and complex}

The roots of the problem are numerous and complex, but one of the chief factors has been rising population in many developing countries which has caused food demand to outstrip production. According to figures in the Academy's report, although food production in the developing countries rose at an unprecedented rate of $2.8 \%$ per year between 1960 and 1975, demand for food increased by $3.5 \%$ per year. Consequently, a growing number of countries have joined the long list of food importers and there has been virtually no increase in per capita food consumption in the developing countries.

And the prospects for population growth don't give much room for optimism. Although there are recent signs that world population growth is beginning to abate, there are likely to be at least 6,000 million mouths to feed by the year 2000, and some $90 \%$ of the growth will take place in the developing countries. World population has recently passed the 4,000 million mark. To feed that many people and provide even a modest increase in per capita consumption will require Herculean efforts. According to the Academy study, the developing countries will need to increase their food production by about $3-4 \%$ per year, while stepping up efforts to reduce their birth rates and providing a more equitable distribution of food.

The task will require a major infusion of funds into research, particularly in the United States, and structural reforms in research programmes and in the political and agricultural systems of many countries.

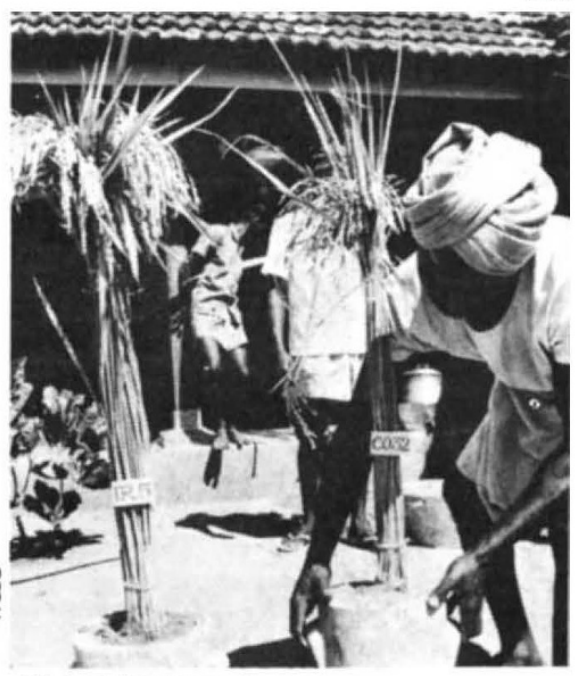

High yield rice under test

Though the committee accepts that the task will not be easy, it states that "a latent political will now exists in numerous countries which could be mobilised in a mutually supporting fashion to commence and support such efforts".

In the past, increases in agricultural production have largely been won in two ways: increasing the acreage under cultivation and improving yields per acre. There have recently been sombre warnings, however, that marginal lands are being taken out of production in some parts of the world because of such problems as desertification and soil erosion and flooding caused by deforestation. The prospects for increasing agricultural acreage are therefore poor, and the Academy study predicts that annual increases in crop area will be unlikely to exceed $1 \%$ per year over the next 25 years. The bulk of the increase in agricultural production will have to come from boosting yields per acre.

The committee offers a shopping list of research programmes which it says should be stepped up to help increase yields. They include the development of fertilisers for use on tropical soils, efforts to improve irrigation and soil conservation, methods of reducing crop losses between the farm gate and the market, the development of more efficient farm systems and the application of biological methods of pest control. Two programmes are expected to be crucial to the long-term prospects for increasing yields, however. They involve boosting the efficiency with which crop plants use solar energy through photosynthesis, and efforts to develop cereal plants capable of utilising nitrogen directly from the atmosphere instead of having it supplied as chemical fertiliser.

At present, some 45 million tons of fertiliser is used per year worldwide. To bring about a doubling in food output during the next quarter century 


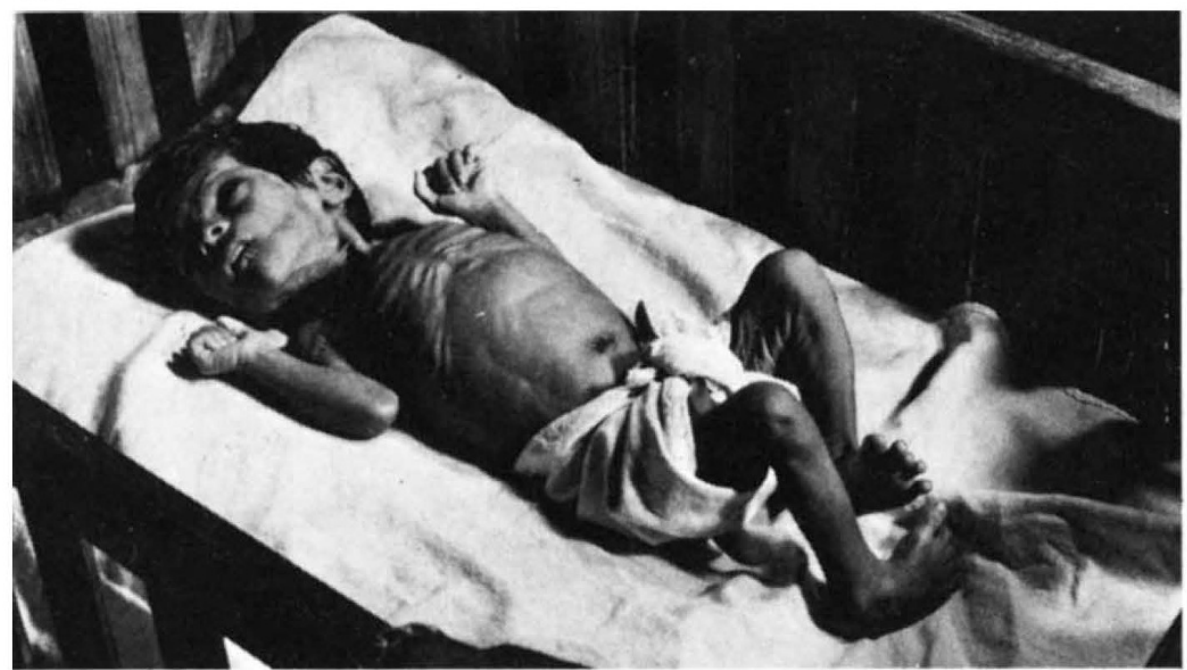

A must to avoid

would require between 2 and 4 times that amount, the Academy committee reckons. That would require about 500 new fertiliser plants, at a cost of some $\$ 50,000$ million at today's prices. Such a vast use of fertilisers would not only be inordinately expensive, but it would also lead to environmental problems through run-off into streams and rivers. Hence the importance of efforts to produce crop plants which can fix their own nitrogen.

It has long been known that leguminous plants have a symbiotic relationship with bacteria living in their root systems which fix nitrogen from the atmosphere and supply it to the plant in a usable form. The immediate goal of research efforts is to improve that symbiotic relationship, thereby increasing yields of leguminous crops without increasing the application of fertilisers. In the more distant future, research efforts are aimed at inducing similar symbiotic associations between bacteria and cereal plants and, perhaps, transferring the genetic capability to fix nitrogen directly into the cells of crop plants.

Each of those goals requires fundamental biological breakthroughs, however, and they may also involve ecological problems. Though researchers are optimistic, there's no guarantee that the required breakthroughs will be forthcoming. The Academy committee recommends a major boost in funding.

The second key effort, boosting photosynthetic efficiency, also requires substantial breakthroughs. At present, most crop plants capture only about $1-3 \%$ of the solar energy they receive, but some plants, such as corn and sugarcane, do much better. Such plants seem to possess a natural mechanism for suppressing the light-aided consumption of stored foodstuffs, and the hope is that research into the underlying processes will lead to methods of increasing the photosynthetic efficiency of other crop plants. The potential is vast: the Academy report reckons that yields of some crops could be boosted by between 50 and $100 \%$ if the research produces results. The report therefore recommends a substantial boost in funds for such research.

Although those two efforts undoubtedly provide the major hopes for a technological fix for increasing food supplies, they are both long-term, longshot efforts. Less glamorous projects, such as improved plant breeding, soil management and pest control are likely to be more certain and yield quicker results: they should thus be pursued equally vigorously, the committee states.

\section{Increased social research}

In the long run, social and organisational changes are likely to prove just as important as technological innovations in alleviating world hunger, and thus the committee urges a sharp increase in social research. In particular, noting that countries with such diverse social and political systems as Taiwan, the People's Republic of China and Sri Lanka have managed to increase food production while lowering birth and death rates, the committee recommends a programme of comparative analysis to see whether any generalisations emerge. "Social science research on food and nutrition lags significantly behind that of biological research because of shortages of skilled personnel, suitable methods of research, data, prior research findings, research funds and effective organisation", the committee states.

Ultimately, political and social changes to combat poverty are likely to be the most effective means to reduce hunger. They are, however, less easy to achieve than changes in the technology of food production. The Academy is nevertheless relatively sanguine about the prospects.
The Academy committee's report calls for a sharp increase in agricultural research on food production and social research on food and nutrition policies. A large proportion of the effort will probably have to be undertaken in the affluent countries, particularly in the United States, but the committee urges that steps be taken to build up the research capacities of the developing countries, and that the international network of research centres be strengthened and expanded. The chief recommendations:

- Research spending on food and nutrition problems should be increased by $\$ 210-230$ million a year in the United States. A large share of the increase should go to the Department of Agriculture, whose research budget is now about $\$ 700$ million a year. The National Science Foundation, the National Institutes of Health and the Agency for International Development should also be given large increases in their research support.

- A new programme of competitive research grants should be established in the Department of Agriculture for work on basic problems such as increasing photosynthetic efficiency and biological nitrogen fixation. (The Ford Administration in fact proposed that $\$ 28$ million be spent on such a programme in fiscal year 1978, but the House Appropriations Committee recently reduced the amount to $\$ 10$ million.)

A new post should be established in the Department of Agriculture with responsibility for research and education.

- The United States should train more researchers from developing countries and provide more direct support for establishing facilities and research institutions in developing countries.

- Two new responsibilities should be added to the Executive Office of the President: an office to develop and maintain a coherent strategy for dealing with world food and nutrition problems, and another to coordinate US and international efforts (in fact, such tasks will probably be given to the Office of Science and Technology Policy.)

The committee briefed White House officials on the recommendations last week and, though the reception was said to be sympathetic, the discussion concerned bureaucratic problems in the Department of Agriculture rather than research strategies.

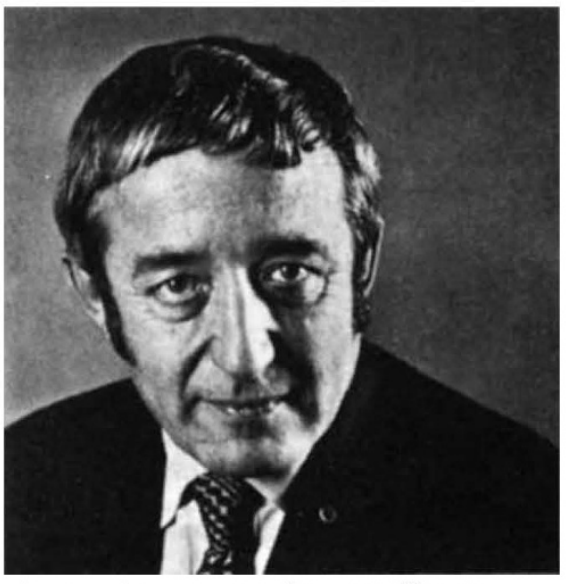

Harrison Brown, committee coordinator 